\title{
Examining Influencer Marketing Practices and Disclosure in Malaysia
}

\author{
Nor Fadzlina Nawi 1, Nur Amalina Faizol 2 \\ 1 Department of Law, \\ Universiti Teknologi MARA, Seremban Campus, Seremban, 70300, Negeri Sembilan, Malaysia \\ 2 Faculty of Law, \\ Universiti Teknologi MARA, Shah Alam Campus, Shah Alam, 40450, Selangor, Malaysia \\ nfadz644@uitm.edu.my, amalinafaizol@gmail.com \\ Tel of 1st Author: +60193838485
}

\begin{abstract}
Recent times have seen social media influencers becoming the foundation of 'influencer' based marketing practices. This phenomenon raises certain legal concerns, including the issue of disclosure. This study examined influencer marketing practices in Malaysia on Instagram and explored Malaysia's need to review its regulation, especially when it comes to disclosure. Although preliminary, the findings of this study give an overview of the marketing practices undertaken by these influencers and the lack of disclosure of 'material connection' between the business or brand and the influencers. It is concluded that Malaysia needs to acknowledge this concern and revised its laws.
\end{abstract}

Keywords: disclosure; influencer marketing; social media; regulation

eISSN: 2398-4287 @ 2021. The Authors. Published for AMER ABRA cE-Bs by e-International Publishing House, Ltd., UK. This is an open access article under the CC BYNC-ND license (http://creativecommons.org/licenses/by-nc-nd/4.0/). Peer-review under responsibility of AMER (Association of Malaysian Environment-Behaviour Researchers), ABRA (Association of Behavioural Researchers on Asians) and cE-Bs (Centre for Environment-Behaviour Studies), Faculty of Architecture, Planning \& Surveying, Universiti Teknologi MARA, Malaysia.

DOI: https://doi.org/10.21834/ebpj.v6iSI5.2941

\subsection{Introduction}

Influencer marketing in the digital age may be a new form of marketing tool in Malaysia, but it is a booming trend. This form of marketing, also known as 'the digital version of mouth marketing' (Sinkwitz, 2016), engages a category of people termed as 'social media influencer' for marketing products or services through the myriad of social media channels, often in exchange for money, or free or discounted products, or services. These so-called 'influencers' are those individuals having a significant number of following on social media platforms, including Twitter, Instagram and Facebook (Smith et al., 2018). Several studies have shown that social media influencers play an important role as a reference group in consumers' purchase behaviour these days due to their popularity or relationship with their followers, which in turn makes marketing through these influencers a success (Barker, 2017; Berger, 2012; Ewers, 2017; Khatib, 2016; Linh, 2018; Low \& Lim, 2012; Smith et al., 2018; Wiley, 2017; Woods, 2016).

With a $132.9 \%$ mobile phone penetration rate in Malaysia, as noted by the Malaysian Communications and Multimedia Commission (MCMC) Internet Users Survey in 2017, marketing through social media influencers could certainly reach Malaysian users. These users' top online activities include text communication (96.3\%), browsing social media (89.3\%) and information access (86.9\%). Out of those who visit social media sites, the survey reported that $97.3 \%$ have Facebook accounts, and $56.1 \%$ have accounts on Instagram. Indeed, even the President of the Malaysia Retail Chain Association, Garry Chua, when speaking to The Star Online in 2018, acknowledged that social media influencers are valuable for businesses today. Many of them have included these influencers in their marketing strategies (Yuen, 2018). Although this marketing trend is a recent phenomenon in the marketing field in Malaysia, marketing agencies have been reported by the media to regularly engaged in such marketing strategy (Dhesi, 2020). Local media have also interviewed a

eISSN: 2398-4287 ( 2021. The Authors. Published for AMER ABRA cE-Bs by e-International Publishing House, Ltd., UK. This is an open access article under the CC BYNC-ND license (http://creativecommons.org/licenses/by-nc-nd/4.0/). Peer-review under responsibility of AMER (Association of Malaysian Environment-Behaviour Researchers), ABRA (Association of Behavioural Researchers on Asians) and cE-Bs (Centre for Environment-Behaviour Studies), Faculty of Architecture, Planning \& Surveying, Universiti Teknologi MARA, Malaysia.

DOI: https://doi.org/10.21834/ebpj.v6iSI5.2941 
couple of influencers who admitted to having turned to social media 'influencing' as a career. These influencers reported regularly being approached to promote products and services in the beauty, sports and lifestyle categories (A Malek, 2018).

However, this phenomenon raises certain legal concerns. According to Faizol \& Nawi (2018), a common legal issue in the usage of social media influencers in marketing in Malaysia is the lack of disclosure of endorsement practices under marketing laws. The issue of disclosure has been extensively touched upon in the media abroad. It has garnered the attention of regulatory agencies such as the U.S. Federal Trade Commission (FTC) and the Italian Competition Authority, which has been very concerned with the practice of hidden advertising by these influencers. In 2018, the FTC started sending reminders to 90 influencers that full disclosure of any 'material connection' with advertised consumer goods or services is a duty, emphasising that truth in advertising and marketing also applies to social media.

Thus far, the lack of full disclosure in influencer marketing practices has become one of the most common violations under marketing laws that has been widely discussed. Studies have shown that influencers' credibility and lack of disclosure in their endorsement practices on their social media accounts have now become rife (Abidin \& Ots, 2016; Gürkaynak, Kama \& Ergün, 2018). In Malaysia, marketing agencies have also started to acknowledge how consumers are now wary of the authenticity and credibility of recommendations made by social media influencers (Dhesi, 2020). However, local lawmakers are slow to keep pace with technological change, including the evolving social media landscape. Inquiries made to the Malaysian Communications and Multimedia Commission (MCMC) in April 2019 revealed that Malaysia has yet to have any specific guidelines or regulations for social media influencers, especially in ensuring that sponsored or advertisement-based posts on social media accounts are clearly labelled and identified. A review of legislation in Malaysia regarding disclosure also shows that the Malaysian marketing industry has been silent on the matter. Although available for regulating traditional marketing and advertisement, current laws in Malaysia are limited in scope and lack detailed guidelines in dealing with influencer marketing. The regulatory framework for Malaysia thus still lags for as long as the significant impact of influencers' marketing activities remains heavily underestimated.

This study thus seeks to provide a preview of influencer marketing practices in Malaysia and assess whether such practices warrant a specific regulation, especially when it comes to disclosure. The study review postings may be categorised as endorsements by selected local social media influencers and assess disclosure in any of these postings. The findings of this study are preliminary and not extensive. However, they would provide an understanding of the subject matter at hand, at least when regulating disclosure in influencer marketing.

For this study, considering the advancement of the USA in dealing with endorsements and disclosures in influencer marketing, the 2018 FTC's 'Endorsements Guides' is heavily referred to in assessing whether disclosure is necessary in the reviewed postings. The FTC Guides provide 35 examples of various endorsement scenarios as a point of reference, especially for the social media influencer in deciding whether to disclose the material connection with the brand, even if businesses gave free products to an influencer in hopes for a positive review from the influencer. If such a connection is not disclosed, the influencer can be held liable for deceptive social media endorsement. The study focuses its assessment on the social media platform; Instagram, for it is currently one of the most popular platforms for influencer marketing in Malaysia (Anymind Group Inc. 2020). Instagram is acknowledged to be a popular influencer marketing platform due to its high levels of user engagement generated from its visual content interface (Evans, Phua, Lim \& Jun, 2017; Jaakonmäki et al., 2017).

The next section of this paper summarises the concept of digital age influencer marketing and the different marketing practices possible on social media, followed by a discussion on the importance of disclosure in influencer marketing. The paper further detailed the methodology adopted for the study, followed by a review of the findings and recommendations.

\subsection{The Need for Disclosure in Influencer Marketing}

The traditional version of influencer marketing existed long before the internet reached our shores. For decades, business has been hiring individuals with a significant social impact, such as celebrities, athletes, and motivators to advertise or endorse products or services through traditional media. However, the emergence of social media networks has now changed the way marketing works profoundly. Modern influencer marketing relies on social media influencers, individuals with a significant social media following, to boost online engagement for the business or brand's endorsed product or service (Barker, 2017; Ewers, 2017; Khatib, 2016; Linh, 2018; Low \& Lim, 2012; Samat et al. 2014; Smith et al., 2018; Wiley, 2017; Woods, 2016).

Determining whether these so-called influencers are genuinely 'influential' is often problematic. However, according to Goanta and Ranchordás (2019), an individual can be considered as an influencer based on several elements; that is the type of industry these influencers operate, the source of their social media popularity, the number of followers and content engagement, and the existence of a business underlying the influencer's operation. Regardless, the most important factor in influencer marketing rests on the ability of these influencers to monetise content on social media.

Paid endorsements and sponsorships are, therefore, a regular occurrence in influencer marketing. Although regulations may vary, this meant, social media influencers engaged in such marketing activities have a duty to disclose their advertising relationships with the businesses, including when the influencer receives a free product and/or compensation in exchange for his or her endorsement, testimonial or review (Boerman, Willemsen, \& Van Der Aa, 2017; Khamis, Ang, \& Welling, 2017; Smink, Boerman, \& Reijmersdal, 2017). Disclosure becomes even more necessary because, unlike the traditional marketing method, in which we recognise that celebrities are paid to promote certain products or services, similar recognisance is often undetectable in influencer marketing. Considering the extent of influence these social media influencers have on at least a majority of their followers, sufficiently disclosing the partnerships between marketers and influencers is vital to increasing transparency. It will also prevent their followers and consumers from feeling deceived 
about a product or service endorsed by the influencer. Legally, Malaysian legislation is yet to cover this concern. In this country, marketing is self-regulatory. The protection provided by the Consumer Protection Act 1999 (CPA) for e-consumers against misleading and deceptive conduct, false representation, and unfair practices does not cover goods or services marketed on social media platforms. Full disclosure of advertising and marketing relationship is imperative under consumer protection laws to avoid misleading and confusing consumers in their purchase decision. This study next explores the sorts of marketing practices currently employed by social media influencers in Malaysia and whether disclosure is evident in influencer marketing practices in Malaysia.

\subsection{Methodology}

In fulfilling the research aims, data were collected, coded and qualitatively analysed from the contents of postings published by selected social media influencers in Malaysia on the Instagram platform from January 2019 to April 2019. For the record, Instagram is a social media platform based on sharing photos and videos, allowing for captions and emojis, and the accounts where these photos and videos are posted can be followed (Hu et al., 2014). On the accounts, the followers can like, comment, share and save the posts, referred to as engagement in its context. This study is a preliminary one, aiming to provide an overview of social media influencers' marketing practices in Malaysia. The study is limited to the content analysis of Instagram postings from ten selected accounts. The sample is relatively small in order to allow an in-depth analysis of the postings. The ten selected social media influencers were shortlisted based on initial search protocols and outcomes via a Google search using the terms 'top influencers \& Malaysia \& 2019'. The search results were filtered, and the top ten influencers with the highest number of followers on their respective accounts were chosen to be reviewed. Although the number of followers does not necessarily represent similar number of engagements, but the criteria is chosen based on the assumption that influencers with a large number of following has greater reach and influence to their followers and consumers in general. Information regarding the name of the influencers and number of followers were compiled and corroborated by examining their Instagram accounts before a final list is presented here in Table 1. Notably, these influencers mostly hailed from a similar type of industry: entertainment and are considered show-business professionals.

Due to the sheer number of posts on the accounts of these top influencers, the investigation is limited to contents posted from January to April of 2019. Overall, 2398 posts from the ten accounts were retrieved and analysed. The postings were browsed and sorted into five categories - personal matters, career-related, products, services, events. Each post is sampled against the 35 examples of various endorsement scenarios suggested by the USA's FTC's 'Endorsements Guides'. Posts likely to be endorsements or reviews are identified based on terms or scenarios used in the postings. The criteria include:

- thanking a brand or business and tagging them in posts,

- posts of products or certain events or place which consists of a 'hashtag' of a certain brand or business or place,

- promoting certain contests of any brand or business,

- reviewing a particular business or brand, including food and beverage and hospitality services.

Posts likely to be endorsements or reviews identified and disclosed by these influencers are also noted. In clarifying the assumption of whether these influencers are involved in endorsement and/or review of product or services, they are also approached in private to probe on their terms and conditions for prospective product and/or service endorsement or review.

\subsection{Findings}

Instagram accounts of the ten chosen Malaysia-based influencers examined (see Table 1) shows that in the four months (January to April) of 2019, several contents posted by them are likely to be some form of product or service endorsements or reviews. However, none of the posts, except by three influencers, indicated paid or sponsored endorsements. Examination of their accounts revealed that most of the posts which contained contents of possible product endorsements or reviews do not carry further information suggesting the paid or sponsorship relationship with the business that engage their services. The summary of the overall findings is tabulated in the following table.

Table 1. Review of Posts by Malaysia-based Top Influencers on Instagram (Jan - Apr 2019)

\begin{tabular}{|l|l|l|l|l|l|l|l|l|}
\hline \# & @username & Name & $\begin{array}{l}\text { Profession/ } \\
\text { Specialty }\end{array}$ & $\begin{array}{l}\text { IG } \\
\text { Followers \# }\end{array}$ & $\begin{array}{l}\text { Latest Number of } \\
\text { Followers (April } \\
\text { 2019) }\end{array}$ & $\begin{array}{l}\text { Number of } \begin{array}{l}\text { Posts Since Jan } \\
2019\end{array} \\
\text { to be an Endorsement/ } \\
\text { Review in 2019 } \\
\text { (April 2019) }\end{array}$ & $\begin{array}{l}\text { Number of Posts Likely to } \\
\text { be an Endorsement/ } \\
\text { Review in 2019 which are } \\
\text { disclosed } \\
\text { advertisement/ } \\
\text { review }\end{array}$ \\
\hline 1 & @ctdk & $\begin{array}{l}\text { Siti } \\
\text { Nurhaliza }\end{array}$ & Singer & $6.2 \mathrm{M}$ & $6.3 \mathrm{M}$ & 537 & 101 & none \\
\hline 2 & @neelofa & Neelofa & $\begin{array}{l}\text { Host, } \\
\text { Actress }\end{array}$ & $6.1 \mathrm{M}$ & $6.2 \mathrm{M}$ & 151 & 67 & none \\
\hline 3 & @noradanish & $\begin{array}{l}\text { Nora } \\
\text { Danish }\end{array}$ & Actress & $5.8 \mathrm{M}$ & $5.9 \mathrm{M}$ & 394 & 60 & none \\
\hline
\end{tabular}




\begin{tabular}{|l|l|l|l|l|l|l|l|l|}
\hline 4 & @zizanrazak869 & $\begin{array}{l}\text { Zizan } \\
\text { Razak }\end{array}$ & $\begin{array}{l}\text { Comedian/ } \\
\text { Actor }\end{array}$ & $5.7 \mathrm{M}$ & $5.9 \mathrm{M}$ & 153 & 26 & None \\
\hline 5 & @schaalyahya & $\begin{array}{l}\text { Scha } \\
\text { Alyahya }\end{array}$ & $\begin{array}{l}\text { Model/ } \\
\text { Actress }\end{array}$ & $4.7 \mathrm{M}$ & $4.8 \mathrm{M}$ & 358 & 124 & 3 \\
\hline 6 & @haniszalikha & $\begin{array}{l}\text { Hanis } \\
\text { Zalikha }\end{array}$ & $\begin{array}{l}\text { Blogger/ } \\
\text { Actress }\end{array}$ & $4.7 \mathrm{M}$ & $4.8 \mathrm{M}$ & 92 & 30 & none \\
\hline 7 & @missfazura & Nur Fazura & Actress & $4.5 \mathrm{M}$ & $4.6 \mathrm{M}$ & 147 & 51 & none \\
\hline 8 & @jannanick & Janna Nick & Actress & $4.4 \mathrm{M}$ & $4.6 \mathrm{M}$ & 167 & 81 & 33 \\
\hline 9 & @elfiraloy & Elfira Roy & Actress & $4.4 \mathrm{M}$ & $4.4 \mathrm{M}$ & 145 & 72 & none \\
\hline 10 & @mfmirafilzah & Mira Filzah & $\begin{array}{l}\text { Host/ } \\
\text { Actress/ } \\
\text { Model }\end{array}$ & $4.3 \mathrm{M}$ & $4.4 \mathrm{M}$ & 254 & 97 & 6 \\
\hline
\end{tabular}

These influencers are active on the platform with regular posting of contents ranging from personal matters, career-related products, services, and personal or career-related events. They posted contents related to products or services observed to be akin to product or service endorsement. Some of these influencers even welcome future negotiation for advertisements (also commonly known as 'paid reviews' amongst Instagram users) from those who visit their account (see example Figure 1). As can be seen on the Instagram account shown in Figure 1, the account holder with 6.7 million followers has left an email address (ads@xx) on her account profile understood to be for inquiries on advertisements. But none of the postings reviewed from the account that is likely to be considered as an endorsement or paid review between January and April 2019 was declared.

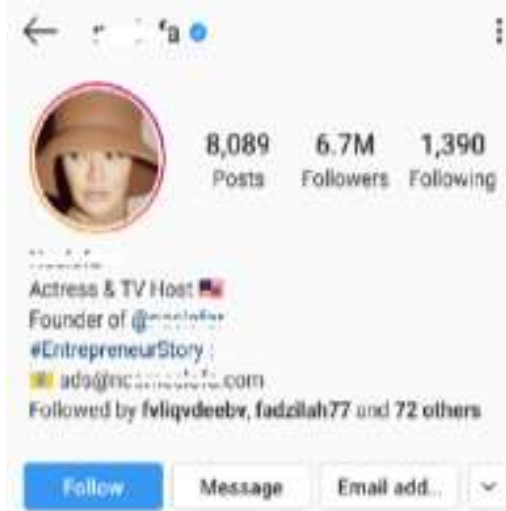

Fig. 1: Sample Profile \& Posts on Instagram (Jan - Apr 2019) (Source: Instagram)

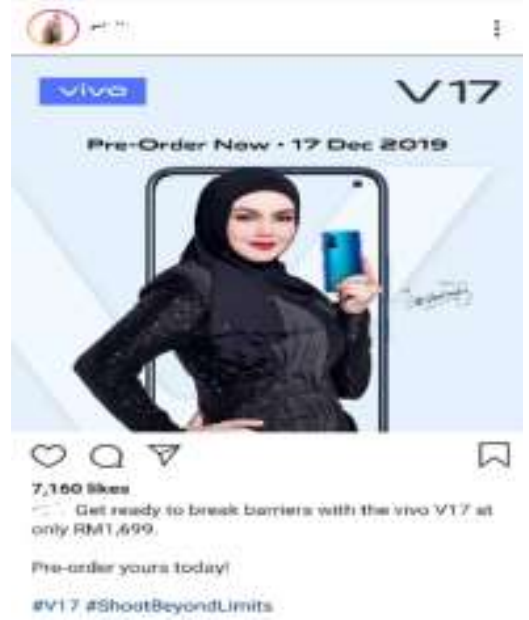

Fig. 2: Sample of Posts on Instagram (Jan - Apr 2019) (Source: Instagram)

The review also shows that most of these influencers do not disclose if any of their posts are sponsored or compensated, even when 
it is the case. This situation can be seen when the influencers are well-known to be the product ambassador of a certain brand (see sample posts in Figure 2). The celebrity shown in Figure 2 is the brand ambassador for the product posted in this particular post. However, no mention was made in the post that it is part of an advertising campaign.

\subsection{Discussion: The Lack of Disclosure}

Based on the findings, most of the local social media influencers reviewed for the study are not shown to have realised the need to disclose their relationship with the brand or marketeers when making any endorsement or paid review. However, when these influencers are approached personally through their account, enquiring if they carry any terms and conditions for a possible endorsement or review of product or service on their social media account, almost all of them responded in the affirmative. Some are nonchalant in immediately exposing the cost of their services. At the same time, some other top celebrities prefer to first review the business' account and product before giving their agreement and charges (for privacy reasons, these correspondences are not attached in this paper).

Some of these influencers may even appear to their followers as genuine or regular users of certain product or services. This lack of disclosure may lead their followers to believe in their authenticity and credibility in reviewing product or services whilst merely endorsing them for businesses and getting compensated for it. Therefore, the lack of disclosure leads to deceit and misleading followers and consumers when making their purchase decisions. Several commentators have stressed that as more consumers nowadays rely on these influencers for their purchase decisions, disclosing ties between the influencer and marketeers has become a duty (eMarketer, 2018; Ray 2017).

These influencers may also be reviewing, promoting, or endorsing products or services they are not an expert of or have never really used, most times failing to disclose these facts. Unlike traditional marketing methods, such as advertisements slots on television, which are commonly recognised as paid celebrities promoting certain products or services, such disclosure is almost absent in influencer marketing, as can be observed in the example of accounts reflected in Table 1. Although the findings are limited and solely based on these selected Instagram accounts and not purported to represent all influencer marketing practices in Malaysia, they gave a disconcerting overview of the situation in Malaysia.

A cursory review of several other accounts on Instagram has also shown that this concern of a failure to disclose is not only exclusive to Malaysia-based top influencers in the study. Several other lesser-known celebrities (also identified as micro-celebrities), as displayed in Figure 3, have shown similar tendencies. Communications observed on this influencer's account proved that her followers (of 277k), being the consumers are not aware that some of the posts were endorsements and not from the influencers' honest review. A commentary left by one, identified as Kambing in Figure 3, gives an overview of the situation. In this instance, had Kambing knew that the influencer's post wearing the 'Surihati Telekung' was a paid review or advertisements, the follower would not have been leaving comments - advising the influencer to hide her religious rituals activities. In subsequent replies, Kambing was somehow ridiculed with statements indicating that the original post was a review. A click to the linked account in the original posting would lead consumers to the product store instead. However, full disclosure of whether the post may be paid reviews or advertisements is almost non-existence.

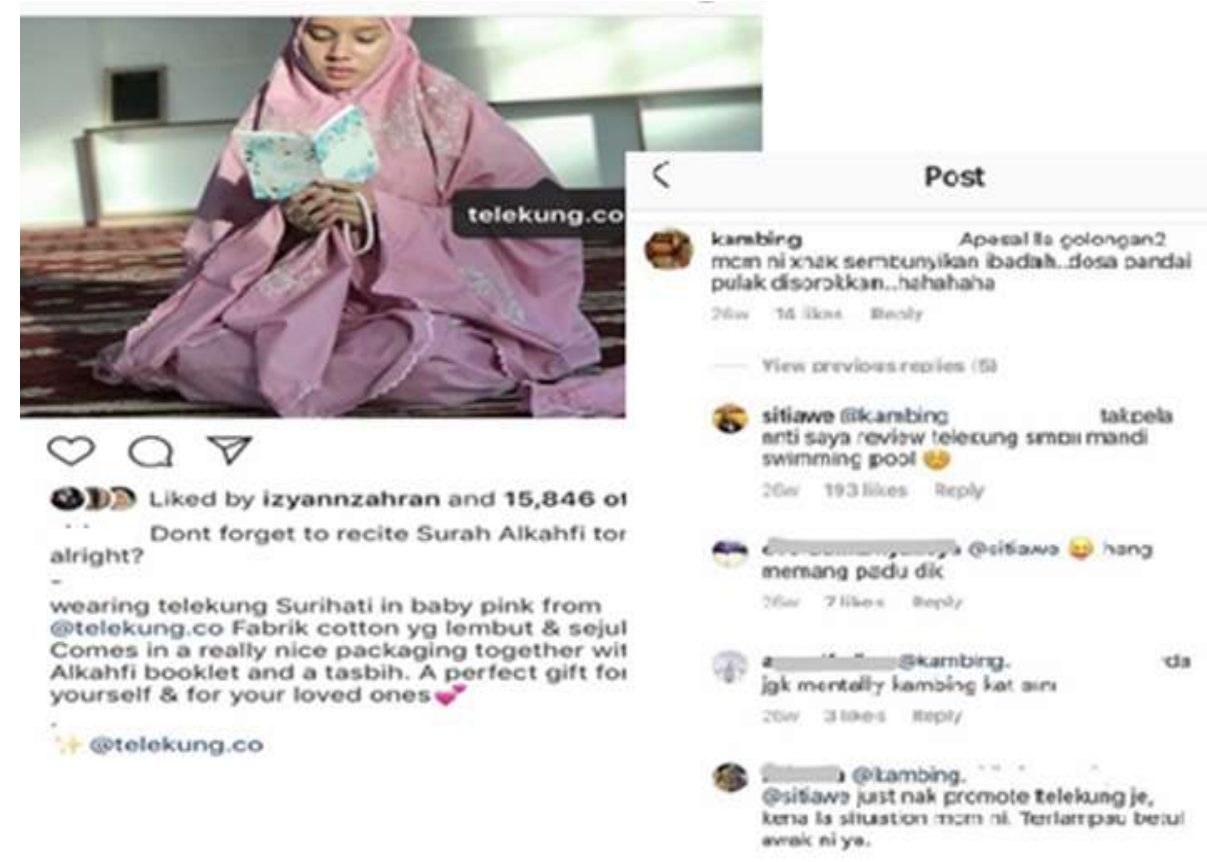

Fig. 3: Sample of Posts Correspondences on Instagram (Jan - Apr 2019) (Source: Instagram) 
Under current marketing laws, those involved in marketing and advertising have a duty to disclose all the relevant information that consumers should know before buying the products or engaging any services to avoid any confusion and ensure that their marketing activities should not be false, misleading, deceptive. Most posts by these social media influencers are devoid of such disclosure.

Full disclosures are meant to provide transparency and honesty for all viewers of the sponsored post. In other words, a material connection between the brands and the influencers need to be disclosed clearly, conspicuously, and broadly to be easily understood in the post. Influencers must let the consumers know that they are being paid to post about a brand or product on their social media accounts. Without full disclosure, the post might appear as if the influencers are posting about their honest opinion or recommendation of the products/services, which can be misleading. Consumers have a right to know if it is an advertisement and not misled into believing that the posts come from the influencers' genuine opinion. Knowing the influencers are paid or being compensated to promote the products will shape how the consumers value the posts and how much weight would be given to the post in making their purchase decision. The influencers reviewed for the study also do not realise that they have certain responsibilities, to be honest to their followers when making endorsements for businesses. This situation is rather alarming considering that they are the most well-known showbusiness professionals in Malaysia and should be well-informed of their role as public figures.

\subsection{Conclusion: The Need for Regulation}

This study has examined a segmented part of influencer marketing practices in Malaysia on the social media platform Instagram. Notably, the study has its limitations. It is a relatively small-scale pilot, qualitative research, and the findings are preliminary. However, its findings provide initial insights into the sorts of marketing practices currently employed by social media influencers in Malaysia and the frequent lack of disclosure of 'material connection' between the business or brands and the influencers. This situation occurs even when postings of contents are likely to be categorised as an endorsement of a product or service. In Malaysia, no regulation requires the influencer to disclose their sponsored/material connection with any business on social media. The lack of regulation for full disclosure in influencer marketing in Malaysia means influencers are not necessarily bound by such duty.

Admittedly, influencer marketing in Malaysia is still considered a new phenomenon. Many Malaysians, including some business and influencers, may still not grasp its whole concept and the legal perspectives. Nevertheless, as this method in marketing is fast becoming a trend, there is a need to re-examine the adequacy of the regulatory framework in Malaysia applicable to this new development, especially when it comes to disclosure. MCMC acknowledge that Malaysian laws, including the Communications and Multimedia Act 1998, Consumer Protection Act 1998, and Medicine (Advertisement \& Sale) Act 1956, have limited scope and protection for consumers. They lack detailed guideline in dealing with social media influencer. However, these influencers are still subject to these laws. While the duty of disclosure may be present under traditional marketing laws, but when it comes to enforcement, the lack of specified regulation may prove to be a challenge in ensuring influencers' compliance with such duty. Further research will also need to be conducted to widen the scope of the data examined and assess the extent to which these non-disclosures affect consumers' purchase decisionmaking in Malaysia.

Furthermore, violation of general laws on marketing continues to be common when these Malaysian-based social media influencers engage in their marketing activities. It is high time, then, for Malaysia to acknowledge this growing concern in influencer marketing and its role in social media and welcome new laws in dealing with them. Future research should then consider best practices and policies from several jurisdictions to develop the relevant law for Malaysia.

\section{References}

Abidin, C., \& Ots, M. (2016). Influencers Tell All? Unravelling Authenticity and Credibility in a Brand Scandal. In Blurring the lines: Market-driven and democracy-driven freedom of expression (p. 153). Nordicom.

AnyMind Group Inc. (2020). State of Influencer Marketing in Asia 2020. https://anymindgroup.com/news/announcement/7784/

Barker, S. (2017). Retrieved November 8, 2019, from medium.com: https://medium.com/@shane_barker/75-influencer-marketing-statistics-that-will-surprise-you-in-2018b11c39a92b36

Barker, S. (2017). Retrieved November 30, 2019, from Influencer Marketing Statistics that will surprise you in 2018: https://medium.com/@shane_barker/75-influencermarketing-statistics-that-will-surprise-you-in-2018-b11c39a92b36 (accessed 30 November 2019)

eMarketer. (2018, February 14). Retrieved from Why Disclosure Is Essential When It Comes to Influencer Marketing: https://www.emarketer.com/content/why-disclosureis-essential-when-it-comes-to-influencer-marketing

Evans, N.J., Phua, J., Lim, J. and Jun, H. (2017). Disclosing Instagram influencer advertising: The effects of disclosure language on advertising recognition, attitudes, and behavioral intent. Journal of Interactive Advertising, 17(2),138-149.

Ewers, N. L. (2017). \#sponsored -Influencer Marketing on Instagram: An Analysis of the Effects of Sponsorship Disclosure, Product Placement, Type of Influencer, and their Interplay on Consumer Responses. Master thesis.

Faizol, N.A \& Nawi, N.F (2018). Arising Legal Concern in Endorsement Practices by Social Media Influencers in Malaysia: A Comparative Perspective. Proceedings of the International Law Conference (iN-LAC 2018) - Law, Technology and the Imperative of Change in the 21st Century, Malaysia, $372-378$. https://doi.org/10.5220/0010051903720378 
Dhesi, D. (2020, Jan 13). How effective is influencer marketing? The Star. https://www.thestar.com.my/business/business-news/2020/01/13/how-effective-is-influencermarketingGoanta, C., \& Ranchordás, S. (2020). The regulation of social media influencers: an introduction. In The Regulation of Social Media Influencers. Edward Elgar Publishing.

Gürkaynak, B., Kama, C., \& Ergün, B. (2018). Navigating the Uncharted Risks of Covert Advertising in Influencer Marketing. Business Law Review, 17-19.

Hu, Y., Manikonda, L., \& Kambhampati, S. (2014, May). What we instagram: A first analysis of instagram photo content and user types. In Eighth International AAA conference on weblogs and social media.

A Malek, N.H. (2018, July 15). Influencing as a career. The Star. https://www.thestar.com.my/news/nation/2018/07/15/influencing-as-a-career

Jaakonmäki, R., Müller, O., \& Vom Brocke, J. (2017, January). The impact of content, context, and creator on user engagement in social media marketing. In Proceedings of the 50th Hawaii international conference on system sciences.

Khamis, S., Ang, L., \& Welling, R. (2017). Self-branding, 'micro-celebrity' and the rise of Social Media Influencers. Celebrity Studies, 8(2), 191-208.

Khatib, F. (2016). The impact of social media characteristics on purchase decision empirical study of Saudi customers in Aseer Region. International Journal of Business and Social Science, 7(4), 41-50.

Ta, L. T. (2018). Influencers' Blogging Patterns and Their Power of Shaping Consumer Purchase Decision: An Analysis from the Consumer's Perspectives

Low, S. F., \& Lim, S. W. (2012). Impacts of celebrity endorser on Malaysian young consumers: an empirical study in the sports industry. SEGi Review, 5(1), 95-114.

Ray, R. (2017). Small Business Trend. Retrieved November 3, 2018 from: https://smallbiztrends.com/2017/10/importance-of-disclosure-in-influencer-marketing.html

Samat, M. F., Hashim, H., \& Yusoff, R. N. R. (2014). Endorser credibility and its influence on the attitude toward social media advertisement in Malaysia. Review of Integrative Business \& Economics, 4(1), 144-159

Sinkwitz, J. (2016). What Is Influencer Marketing?, Retrieved November 30, 2019, from: https://intellifluence.com/blog/what-is-influencer-marketing

Smink, A. R., van Reijmersdal, E. A., \& Boerman, S. C. (2017). Effects of brand placement disclosures: An eye-tracking study into the effects of disclosures and the moderating role of brand familiarity. In Advances in advertising research VIII (pp. 85-96). Springer Gabler, Wiesbaden.

Sterling, G. (2017), Survey: Most consumers unaware that paid influencer posts are \#ads. Retrieved February 26, 2019 from: https://marketingland.com/survey-consumersunaware-paid-influencer-posts-ads-227021

Smith, B. G., Kendall, M. C., Knighton, D., \& Wright, T. (2018). Rise of the brand ambassador: Social stake, corporate social responsibility, and influence among the social media influencers. Communication Management Review, 3(01), 6-29.

The Malaysian Communications and Multimedia Content Code (2014)

The Malaysian Reserve. Social media influencers remain digital marketing choice for local brands. Retrieved March 14 , 2019 from: https://themalaysianreserve.com/2019/03/14/social-media-influencers-remain-digital-marketing-choice-for-local-brands/

Wiley, D. (2017). Turning Millennial Prospects Into Customers. Retrieved May 30, 2019 from: https://www.business2community.com/online-marketing/turning-millennialprospects-customers-01852954\#DIdMi2GuoP3Wsfju.97

Woods, S. (2016). \# Sponsored: The emergence of influencer marketing.

Yuen, M. (2018, 15 July). Liked by Many. The Star online. Retrieved October 20, 2019 from: https://www.thestar.com.my/news/nation/2018/07/15/liked-by-many-socialmedia-influencers-are-a-force-to-be-reckoned-with-in-promoting-businesses-today 